\title{
AN OBSERVATIONAL STUDY OF MEDICATION ERRORS AMONG PSYCHIATRIC PATIENTS IN A TERTIARY CARE HOSPITAL
}

\author{
REENU JOSE ${ }^{1}$, JESNA MARIAYAM ${ }^{1}$, KRISHNAVENI $\mathrm{K}^{2 *}$, SHANMUGA SUNDARAM $\mathbf{R}^{3}$, SAMBATHKUMAR $\mathbf{R}^{4}$ \\ ${ }^{1,2}$ Department of Pharmacy Practice, J.K.K. Nattraja College of Pharmacy, Kumarapalayam, Tamil Nadu - 638 183, India. ${ }^{3}$ Department of \\ Pharmacology, J.K.K. Nattraja College of Pharmacy, Kumarapalayam, Tamil Nadu - 638 183, India. ${ }^{4}$ Department of Pharmaceutics, J.K.K. \\ Nattraja College of Pharmacy, Kumarapalayam, Tamil Nadu - 638 183, India. Email: venidhiya@gmail.com
}

Received: 30 May 2018, Revised and Accepted: 19 July 2018

ABSTRACT

Objective: The objective of this study is to evaluate the common medication error (ME), and its causes, category, and severity by using suitable questionnaire.

Methods: A prospective observational study was carried out for 6 months in a psychiatric department. Demographic data, clinical history, and complete prescription were noted.

Results: A total of 120 psychiatric cases were collected, among that 116 MEs were identified in which male patients were 64 (55\%) and females 52 (44.8\%). The number of MEs occurred due to physician was 67 (57.7\%), due to nurses was 15 (12.9\%), and combined was 38 (32.7\%). Incomplete prescription was the main type of error that we found. About $43.1 \%$ of the error we identified was informed to the staff and and no specific action was needed for $37.1 \%$ of errors. In our study, we found that majority of 54 (46.5\%) errors were categorized under category B, but there was no harm to the patient.

Conclusion: The present study concluded that most of the patients admitted in the psychiatry department would experience MEs. Clinical pharmacist can play a major role in the early detection and prevention of MEs and thus can improve the quality of care to the patients.

Keywords: Medication errors, Morbidity, Mortality, Psychiatry.

(C) 2018 The Authors. Published by Innovare Academic Sciences Pvt Ltd. This is an open access article under the CC BY license (http://creativecommons. org/licenses/by/4. 0/) DOI: http://dx.doi.org/10.22159/ajpcr.2018.v11i11.27601

\section{INTRODUCTION}

Safety is a global idea that encompasses performance, protection of care, reactivity of caregivers, and pleasure of sufferers and family. Patient protection has emerged as a major goal for health-care development. The idea of quality has advanced from a method grounded within the physician-patient relationship to broader techniques related to the health-care community, concept of efficiency, and moral access to care [1]. Medication error (ME) is defined as "any preventable event that may cause or lead to inappropriate medication use or patient harm while the medication is in the control of the healthcare professional, patient. Such events may be related to the professional practice, healthcare products, procedures, and systems including prescribing, order communication, product labeling, packaging, compounding, dispensing, distribution, administration, education, monitoring, and use" [2]. ME in psychiatric patients, especially in long-term care facilities, is often trained in self-administration of medications to increase their self-care and to improve their compliance. However, psychiatry patients are extraordinarily at risk of medication mistakes as they are prescribed with complex medication regimen, may be non-compliant, and resist medicinal administration or even be violent. Medication administration to psychiatric inpatients is a demanding situation when compared with other in patients. Evidences from a plethora of resources throw light onto a range of adverse drug events (ADEs) which are due to MEs from psychiatric drugs [3]. MEs might also occur at any level of prescribing, documenting, or management. Furthermore, MEs also contribute to morbidity, mortality, and extended fitness care prices. Mistakes can happen in all stages of care technique from diagnosis to drug management. Blunders arise as a result of two types of failure; the right action does not proceed as meant (an error of execution) or the unique meant action is not accurate (errors of planning). ADEs and MEs are spotted as a crucial and extensive trouble in modern health center settings, inflicting damage as well as avoidable morbidity and mortality [4].

MEs represent the largest single cause of errors in the hospitals, which can be result from the interaction of multiple factors including nature of works environment, difficulty of tasks involved, lack of knowledge on MEs, lack of experience, and lack of required equipment. It is clinically evident that both individual factors contribute almost the same to the ME occurrence [5].

The most common errors have been unauthorized tablet crushing, omission without a valid cause, and failure to file administration. Direct observation is useful, and sensitive technique for detecting medication administration errors in psychiatry is found useful [6]. MEs are one of the most common types of patient incidents worldwide that may cause harm to the patients. To our knowledge, few studies have been completed in psychiatric health center placing which Status on MEs in more ranges of the scientific device. A specific estimation of kinds and capability severity of errors are wanted to select relevant interventions to lessen the MEs. The existing studies were undertaken to understand different kinds of ME in psychiatric prescriptions. This present study aimed to evaluate and categorize the ME occurred in the psychiatric department of a tertiary care hospital.

\section{METHODS}

The prospective observational study was carried out for a period of 6 months in a tertiary care hospital, Erode, Tamil Nadu. The ethical clearance for the study was obtained from the Institutional Ethical Committee. Based on inclusion (patients admitted to the psychiatric department during the study period) and exclusion criteria (patients with other comorbid conditions, pregnant, and lactating women were 
excluded), patients with psychiatric disorders were selected. A separate questionnaire form was prepared to record patient's demographic details. After obtaining informed consent form from the patient, the demographic data such as age, gender, educational status, diagnosis, and prescriptions were collected using a suitable questionnaire form. A total of 120 prescriptions were collected among those 116 prescriptions with MEs. The errors were categorized according to the NCC MERP and categorizing the MEs based on the severity.

\section{RESULTS}

A total of 120 psychiatric cases were collected, in which 65 (54\%) were males and $55(45 \%)$ were females. MEs identified in male patients were $64(55 \%)$ and in females $52(44.8 \%)$.

Most of the MEs found in male patients were $(27,23.2 \%)$ in the age group of 21 to 30 years and in female patients were $(18,15 \%)$ in the age group of 31 to 40 years. More number of psychiatric patients were illiterate $40(33.3 \%)$, primary level $12(10 \%)$, secondary level $18(15 \%)$, higher secondary 35 (29\%), and only 15 (12.5\%) graduates. About $85(70.8 \%)$ of the cases that collected were new cases, among that $35(29.1 \%)$ were rehospitalized cases.

Most of the psychiatric patients admitted in the hospital were due to the certain events or shock that occurred during their lifetime. Among that, $65(54.1 \%)$ patients were admitted due to life events, 35 (29.1\%) due to alcohol/smoking, and $15(12.5 \%)$ due to substance abuse. Among different types of psychiatric disorders, majority of the cases were found to be schizophrenia $45(37.5 \%)$, followed by substance related Disorder 28 (23.3\%), bipolar disease 22 (18.3\%), depression $15(12.5 \%)$ and least one anxiety disorder $10(8.3 \%)$.

Among the 120 patients, more number of errors occurred due to prescription $74(63.7 \%)$ and administration errors $33(28.4 \%)$ and the least one found was dispensing errors $10(8.8 \%)$. Most of the MEs were due to incomplete prescription 62 (53.4\%), followed by wrong time error 16 (13.7\%), wrong dose error 20 (17.2\%), omission error $4(3.4 \%)$, and wrong frequency $2(1.72 \%)$. About $50(43.1 \%)$ errors we found were informed to the staff and no further action was needed for 43 (37\%) errors and 19 (16.3\%) of errors were due to wrong drug frequency.

In our study, it was found that the majority of errors were categorized under category B 54 (46.5\%), but there was no harm to the patient.

\section{DISCUSSION}

MEs are the serious problems in health care and can be a source of significant morbidity and mortality in health-care settings. MEs are probably the most common type of patient safety incidents worldwide and may cause harm to the patients, distress to medical staff, and cost to the health-care system. An average of one or more MEs occurs per hospitalized patient per day.

In our study, a total of 120 prescriptions with psychiatric diseases were collected from the hospital for 6 months, of which 65 (54\%) were male and $55(45 \%)$ female patients (Table 1). Similar results were obtained from the study conducted by Ahmed et al., (2015) and showed that, of 264 patients, 180 were male patients and 84 female patients. In this study, more number of patients affected with MEs were males than females [7]. A study conducted by Anandhasayanam et al., (2016) showed that the error cited was 269 in relation to both categories of male and female patients. In male patients, $80.3 \%$ prescription errors were present and in female (19.7\%) [8]. Similar findings were obtained from the study conducted by Akhil et al., (2017) which revealed that the MEs were more in males than in females [9].

The demographic reports of the present study showed that higher incidence of MEs in male patients $(27,23.2 \%)$ ranges from 21 to 30 years of age followed by $41-50$ years $(19,15.8 \%)$ and $31-40$ years $(15,12.9 \%)$ and in female patient age ranges from 31 to 40 years
$(18,15 \%)$ followed by $21-30$ years $(16,13.3 \%)$ and $41-50$ years $(13,10.8 \%)$ (Table 2). Our study findings were inconsistent with the previous study conducted by Rebeca (2012) from Massachusetts board of registration in pharmacy which showed that a higher incidence of MEs in patients ranged between 31 and 40 years of age [10].

The majority of the patients stayed in hospital for more than 10 days were 56 , and only 19 patients stayed there for more than 1 month. A study conducted by Sungkyu et al., (2012) had shown the prediction of length of hospital stay among psychiatry patients using HLM models. The percentage of the variance defined the duration of hospital stay became attributable to the health facility characteristics turned into $84 \%$. We observed that the education status of most of the patients admitted in the hospitals was illiterate 40 (33.3\%), which was followed by a secondary level $18(15 \%)$, primary level $12(10 \%)$, and graduates $12(10 \%)$ (Table 3) [11]. Similar results were obtained from the study conducted by Yvonne et al., (2002), and in their study, educational status showed that $62 \%$ were illiterates, while $36.7 \%$ had primary or secondary education and only $0.43 \%$ were graduates. Occupational status revealed that majority $60.9 \%$ was housewives, $20.3 \%$ were retired, $3.4 \%$ were unemployed, and the rest were engaged in some occupations [12].

In our study, most of the cases that we collected were newly admitted cases $85(70.8 \%)$, and $35(29.1 \%)$ of the cases were rehospitalized cases (Table 4). Similar results were obtained from the study conducted by Parikh et al., (2014) about rehospitalization in psychiatric patients. They found that it was more in schizophrenia patients. This implies a substantial rate of reoccurrence in psychiatry. A total of 50 cases were collected, among that 27 cases were readmitted and 23 cases were new admission [13].

During the study period, 65 (54.1\%) of the patients were admitted due to life events (stress, work related, and family related), 35 (29.1\%) due to alcohol/smoking, and 15 (12.5\%) due to brain defect/infections. In a previous study conducted by Julia et al., (2017), stated the main reason for hospital admission related to mental disorders explicit causative beliefs regarding work (47\%), social atmosphere (46\%), the self $(35 \%)$, negative life events(29\%), stress $(24 \%)$, childhood (17\%), and physical complaints(17\%). Work-related stress was the most frequently mentioned causal belief for depression in all age groups [Table 5] [14]. In a study conducted by Samiya et al., (2016), any initiative to reduce the prescription error rate must involve knowledge of why, where, and when these errors occur. Inadequate knowledge of pharmacology will obviously predispose to poor prescribing, but environmental factors such as time, pressures, staff shortages, and fatigue can also be the contributory causes [15].

Among 120 psychiatric cases, majority were found to be schizophrenia cases $45(37.5 \%)$, followed by substance-related disorder 28 (23.3\%) and bipolar disorder $22(18.3 \%)$ and the least were depression $15(12.5 \%)$ and anxiety disorder 10 (8.3\%) (Table 6). Similar results were obtained from a study conducted by Sarumathy et al., (2014) and reported that about $20(40 \%)$ cases were diagnosed with schizophrenia [16].

On prescription analysis, risperidone $22(88 \%)$ was the most common prescribed drug followed by diazepam $21(84 \%)$, sodium valproate 19 (76\%), haloperidol 17 (68\%), and trihexyphenidyl 19 (76\%). Similar results were obtained by the study conducted by Ahmed et al., (2015), who reported that risperidone $(46.6 \%)$ was the most commonly prescribed drug in psychiatry patients [7]. Padmini et al., 2007, conducted the study of prescription pattern of psychotropic drugs in hospitalized schizophrenic patients in a tertiary care hospital. The author concluded that risperidone $31.9 \%$ was the most common prescribed drug than trihexyphenidyl $20.3 \%$ and haloperidol $10 \%$ [17].

Our study showed that more number of errors occurred due to prescription 16 (64\%) followed by administration errors 7 (28\%). Benjamin et al., (2003) conducted the study about the distribution of 
Table 1: Gender-wise distribution of MEs

\begin{tabular}{lllll}
\hline Sl.no & Gender & $\begin{array}{l}\text { Number of } \\
\text { patients }(\mathbf{n = 1 2 0})\end{array}$ & $\begin{array}{l}\text { Number of } \\
\text { MEs }(\mathbf{n = 1 1 6})\end{array}$ & Percentage \\
\hline 1 & Male & 65 & 64 & 55 \\
2 & Female & 55 & 52 & 44.8 \\
\hline
\end{tabular}

Table 2: Age-wise distribution of MEs

\begin{tabular}{llll}
\hline Sl.no & $\begin{array}{l}\text { Age group } \\
\text { (in year) }\end{array}$ & $\begin{array}{l}\text { MEs in male } \\
\text { patients n=64 (\%) }\end{array}$ & $\begin{array}{l}\text { MEs in female } \\
\text { patients n=52 (\%) }\end{array}$ \\
\hline 1 & $10-20$ & $2(0.8)$ & $3(2.5)$ \\
2 & $21-30$ & $27(23.2)$ & $16(13.3)$ \\
3 & $31-40$ & $19(15.8)$ & $18(15)$ \\
4 & $41-50$ & $15(12.9)$ & $13(10.8)$ \\
5 & $51-60$ & $1(0.8)$ & $2(1.6)$ \\
\hline
\end{tabular}

MEs: Medication errors

Table 3: Educational status of the patient

\begin{tabular}{lll}
\hline Sl. no & $\begin{array}{l}\text { Educational } \\
\text { status }\end{array}$ & $\begin{array}{l}\text { Number of patients } \\
\mathbf{n = 1 2 0}(\mathbf{\%})\end{array}$ \\
\hline 1 & Primary & $12(10)$ \\
2 & Secondary & $18(15)$ \\
3 & Higher secondary & $35(29)$ \\
4 & Graduate & $15(12.5)$ \\
5 & Illiterate & $40(33.3)$ \\
\hline
\end{tabular}

Table 4: Distribution of cases

\begin{tabular}{lll}
\hline Sl.no & Types of cases & $\begin{array}{l}\text { Total number of cases } \\
\mathbf{n = 1 2 0}(\boldsymbol{\%})\end{array}$ \\
\hline 1 & Newly diagnosed cases & $85(70.8)$ \\
2 & Relapsed cases & $35(29.1)$ \\
\hline
\end{tabular}

Table 5: Risk factors of psychiatric patients

\begin{tabular}{lll}
\hline Sl.no & Risk factors & Number of patients $\mathbf{n = 1 2 0}(\%)$ \\
\hline 1 & Life events & $65(54.1)$ \\
2 & Alcohol/smoking & $35(29.1)$ \\
3 & Substance abuse & $15(12.5)$ \\
4 & Others & $5(4.1)$ \\
\hline
\end{tabular}

errors, among that more number of errors was under administration $66 \%$ which was followed by prescription errors $11 \%$ and dispensing errors $1 \%$, and our study findings were inconsistent with this study [18]. Previous study by Ann et al., (2013) reported that prescribing errors were most observed error than dispensing and administration errors. This result is relate with our study report [19].

A total of 120 cases were collected, among that 116 (96.6\%) prescriptions were found with error and 4 (3.3\%) were found without error. Previous study by Akhil et al., (2017) reported that, out of 200, 122 prescriptions were found with error and 78 didn't have any error. (Table 7) [9].

The most common factor that related to ME includes 67 (57.7\%) physician related (due to workload, stress, etc.), 15 (12.9\%) nursesrelated errors, and 32 (27.5\%) improper communication errors. Similar findings were obtained from the study conducted by Arife $e t$ al., (2015) who reported the underlying reasons of MEs include increased workload (49.7\%), inadequate number of staff (36.5\%), and syndrome (25.6\%) [20].
Table 6: Types of psychiatric disorders

\begin{tabular}{lll}
\hline Sl.no & Psychiatric disorders & Number of cases (\%) \\
\hline 1 & Anxiety disorders & $10(8.3)$ \\
2 & Bipolar disorder & $22(18.3)$ \\
3 & Depressive disorder & $15(12.5)$ \\
4 & Schizophrenia & $45(37.5)$ \\
5 & Substance related disorders & $28(23.3)$ \\
\hline
\end{tabular}

Table 7: Types of errors in different stages of the medication process

\begin{tabular}{lll}
\hline Sl.no & $\begin{array}{l}\text { Stages in medication } \\
\text { process }\end{array}$ & $\begin{array}{l}\text { Number of errors occurred } \\
\mathbf{n = 1 1 6}(\%)\end{array}$ \\
\hline 1 & Prescribing & $74(63.7)$ \\
2 & Dispensing & $10(8.8)$ \\
3 & Administration & $33(28.4)$ \\
4 & Transcribing & 0 \\
\hline
\end{tabular}

Table 8: Types of MEs observed in psychiatric patients

\begin{tabular}{lll}
\hline Sl.no & Types of MEs & Number of ME $\mathbf{n = 1 1 6}(\%)$ \\
\hline 1 & Incomplete prescription & $62(53.4)$ \\
2 & Wrong time error & $16(13.7)$ \\
3 & Wrong dose error & $20(17.24)$ \\
4 & Wrong dosage error & $9(7.75)$ \\
5 & Omission error & $4(3.4)$ \\
6 & Wrong frequency & $2(1.72)$ \\
7 & Wrong duration & $3(2.58)$ \\
8 & Monitoring errors & 0 \\
\hline
\end{tabular}

MEs: Medication errors

Table 9: Types of study interventions

\begin{tabular}{lll}
\hline Sl.no & Types of interventions & $\begin{array}{l}\text { Number of } \\
\text { interventions (\%) }\end{array}$ \\
\hline 1 & Informed staff who made error & $50(43.1)$ \\
2 & No action needed & $43(37.0)$ \\
3 & Changed correct drug/frequency & $19(16.3)$ \\
4 & Communication process improved & $4(3.4)$ \\
\hline
\end{tabular}

According to our study, we found that the more number of MEs occurred due to physician was 67 (57.7\%), due to nurses was 15 (12.9\%), and both the physician and nurses combined was 38 (32.7\%). Since most of the prescriptions were incomplete and with illegible handwriting, physicians were more responsible for the occurrence of MEs followed by nurses and both the physicians and nurses. Similar results were obtained from the study conducted by Anandhasayanam et al., (2016) and Elden et al., (2014) who reported that most of the MEs were occurred due to physicians. From this study, we found that the more number of MEs were due to incomplete prescriptions 62 (53.4\%), followed by wrong time error 16 (13.7\%), wrong dose error $20(17.2 \%)$, omission error $4(3.4 \%)$, and wrong frequency $2(1.72 \%)[8,21]$. Similar findings were obtained from the study conducted by Nair and Srivastava (2012) who reported that more number of errors were due to frequency missing/dose missing (30\%), followed by wrong drug (20\%) and others (10\%). Karin et al., (2016) [23] reported that majority of errors were due to incorrect dose $41 \%$, wrong patient $13 \%$, omission of drug $12 \%$. (Table 8).

Our study concluded that more number of errors happened due to lack of knowledge or heavy workload 62 (53.4\%), illegible prescriptions 32 (27.5\%), and miscommunication 20 (17.24\%). Similar results obtained from a study conducted by Arife et al., (2015) [20] reported that most of the MEs are due to increased workload (49.7\%), inadequate number of staff (36.5\%), and burnout syndrome (25.6\%) [22]. 
Table 10: Severity level assessment of MEs

\begin{tabular}{llll}
\hline Sl.no & Level of severity & Category & Number of MEs (\%) \\
\hline 1 & No error & Category A & $39(33.6)$ \\
2 & Error, no harm & Category B & $54(46.5)$ \\
& & Category C & $23(19.8)$ \\
& & Category D & $1(0.86)$ \\
& \multirow{2}{*}{ Error, harm } & Category E & 0 \\
& & Category F & 0 \\
& & Category G & 0 \\
4 & \multirow{2}{*}{ Error, death } & Category H & 0 \\
\hline
\end{tabular}

MEs: Medication errors

About 50 (43.1\%) errors we found were informed to the staff, no further action was needed for 43 errors and 19 (16.3\%) errors were due to wrong drug/frequency which was changed to correct frequency and correct drug. In a study conducted by Rahbi et al., (2014) [24] only 688 interventions were due to prescribing errors, of which $40.5 \%$ interventions were done in changing the medication order of clarifying the medicine. $14.9 \%$ of the interventions were related to administrative issues, and $8.7 \%$ of the interventions were related to the selection of medications as well as errors due to ignorance of history of patients (Table 9) [23].

Our study determined that majority of errors were coming under category B, but there is no harm to the patient. The National Coordinating Council for ME reporting and prevention proposed ME index was used to assess the severity of ME. Ganeshan et al. (2015) [5] reported that, among 69 MEs, 8 (11.59\%) were under category of no error which is subcategory A, 60 (86.95\%) errors were under the category error, and no harm which comes under subcategory B, and they stated that this was because of the carelessness of the health-care professional working in the department (Table 10) [4].

\section{CONCLUSION}

The present study concluded that mostly all the patients admitted in the psychiatry department would experience MEs. Most of the errors were found to be under category B (error occurred but it did not reach the patient) and category A (events have the capacity to cause error) according to NCC MERP classification.

Errors reported in this study clearly showed that there were multiple factors responsible for MEs including incomplete prescriptions (inappropriate use of decimal), illegible handwriting, heavy workload, lack of patient education, and short supply of medicines. The study was highlighted to pay attention to prescription writing and reduce the practice of inappropriate prescription through the provision of appropriate unbiased information to health professional.

Due to the heavy workload of the health-care professionals, there is always a possibility for the occurrence of errors due to rectifiable mistakes by different professionals at different circumstances, and making necessary interventions can well reduce the incidence of MEs. Clinical pharmacist can play a major role in the early detection and prevention of MEs and thus can improve the quality of care to the patients.

\section{ACKNOWLEDGMENT}

We express our sincere gratitude toward the coworkers, study participants, and departmental staffs for their valuable suggestions.

\section{AUTHORS' CONTRIBUTION}

RJ and JM contributed to data collection and manuscript writing; KK contributed to study design, follow-up, and final review; SSR contributed in final review; and SR contributed in approval.

\section{CONFLICTS OF INTEREST}

Authors declare no conflicts of interest.

\section{REFERENCES}

1. Garrouste-Orgeas M, Philippart F, Bruel C, Max A, Lau N, Misset B. Overview of medical errors and adverse events. Ann Intensive Care 2012;2:1-39

2. Karna K, Sharma S, Inamdar S, Bhandari A. Study and evaluation of medication errors in a tertiary care teaching hospital - A baseline study. Int J Pharm Pharm Sci 2012;4:587-93.

3. Sahithi KH, Mohammad I, Reddy JM, Kishore GN, Ramesh M, Sebastian J. Assessment of medication errors in psychiatry practice in a tertiary care hospital. Int J Pharm Sci Res 2015;6:226-32.

4. Ganeshan S, Boguda VA, Alex AR, Anusha B. A prospective study on medication errors in a general hospital. Pharm Lett 2015;7:47-50.

5. Khowaja K, Nizar R, Merchant RJ, Dias J, Malik A. A systematic approach and tracking and reporting of medication error at a tertiary care university. Ther Clin Risk Manag 2008;4:673-9.

6. Roseman C, Booker JM. Workload and environmental factors in hospital medication errors. J Nurs Res 1995;44:226-30.

7. Ahmed T, Sharma S, Ali S, Sachdev D, Sharma R, Jaiswal M. Drug utilization pattern in psychiatry outdoor patients at tertiary care teaching hospital of Bastar region. Int J Pharm Res 2015;5:98-103.

8. Anandhasayanam A, Senthilkumar N, Kannan S, Sathik MZ, Joseph AM. A prospective study of medication errors in the diabetology and general medicine department of a multispeciality hospital. Int $\mathbf{J}$ Pharm Res Rev 2016;5:6-12.

9. Akhil N, Thomas PP, Shivaraj DR, Thomas SM, Londhe SP. Assessment, evaluation and analysis of the medication errors of a tertiary care teaching hospital of a South Indian city. Asian J Pharm Clin Res 2017;10:161-5.

10. Rebeca RC. Medication error study overview - Massachusetts board of registration in pharmacy. PMC 2012;2:10-2.

11. Sungkyu L, Aileen BR, Elizabeth LN. Length of inpatient stay of persons with serious mental illness: Effects of hospital and regional characteristics. Psychiatr Serv 2012;63:889-95.

12. Yvonne SP, Ajoy E, Rajesh D, John F. Geriatric patients attending tertiary care psychiatric hospital. Indian J Psychiatry 2002;44:326-31.

13. Parikh MN, Parikh NC, Patel PR. Re-hospitalization in schizopherinia: Socia demographic and cilnical corrlates. Int J Med Res Rev 2014;2:178-84.

14. Julia LM, Holger S, Anna LB. what do patients think about the cause of their mental disorder? A qualitative and quantitative analysis of causal beliefs of mental disorder in inpatients in psychosomatic rehabilitation. PLoS One 2017;6:310-400

15. Samiya NK, Sibi J, Sasidharan P. A study of clinical pharmacist initiated intervention for the optimal use of medications in a neonatal intensive care unit (NICU) of a tertiary care hospital, South India. Int J Pharm Pharm Sci 2016;8:23-6.

16. Sarumathy S, Menaka K, Samuel GP, Ravichandiran V. A study on drug use pattern and adverse drug reactions of anti - Psychiatric medications in a psychiatry specialized hospital. Int J Pharm Pharm Sci 2014;6:332-4.

17. Padmini DD, Amarjeeth R, Sushma M, Guido S. Prescription patterns of psychotropic drugs in hospitalized schizophrenic patients in a tertiary care hospital. Calicut Med J 2007;5:224-9.

18. Benjamin CG, Robert G, Constance WJ, David WB. Use of chart and record reviews to detect medication errors in a state psychiatric hospital. Psychiatric Serv 2003;54:677-81.

19. Ann L, Soerensen, Marianne L, Lars PN, Birgitte KP, Jan M. The medication process in a psychiatric hospital: Are errors a potential threat to patient safety? Risk Manag Healthc Policy 2013;6:23-31.

20. Arife U, Silay K, Sema A, Didem SD. Medication errors in chemotherapy preparation and administration: A survey conducted among oncology nurses in turkey. Asian Pac J Cancer Prev 2015;16:1699-705.

21. Elden NM, Ismail A. The importance of medication errors reporting in improving the quality of clinical care services. Glob J Health Sci 2016;8:243-51

22. Nair A, Srivastava M. Prescription errors in psychiatry. Int J Med Update 2013;8:70-8.

23. Karin SB, Monica B, Eva AK, Lina B, Johanna U. Medication errors as malpractice - A qualitative content analysis of 585 medication errors by nurses in Sweden. BMC Health Serv Res 2016;16:431-36.

24. Ranbi HA, Al-Sabri RM, Havagiry RC. Interventions by pharmacist in out - Patient pharmaceutical care. Saudi Pharm J 2014;22:101-6. 